\title{
Predictable Influence of IoT (Internet of Things) in the Higher Education
}

\author{
Majid Bayani Abbasy and Enrique Vílchez Quesada
}

\begin{abstract}
Internet of things (IoT) is a relatively an emergent technology that facilitate interaction between the real and virtual objects. As it develops and matures, it grows in scale and dimension influences the context of our life such as the education, in particular higher education; this article focuses on a research associated with the predictable impact of IoT in the superior education. A theoretical analysis along with a statistical study is explored in this paper. The theoretical and statistical results showed non-ignorable influence of the IoT in the education ecosystem in terms of the learning and managing factors. In some cases, such as the hyper- connectivity, collaboration and research opportunities the effect is significant. Emergent technologies such as the IoT at present are rapidly developing in the digital world and transforming traditional education system into a scalable, adaptable with rapid dynamic changes, flexible and more efficient E-learning with a topology where the huge number of physical and virtual interacting objects are involved in the process of learning. It is projected the IoT will make possible to develop the intelligent E-learning systems which can predict and determine the particular educational needs of the students, based on the study of data obtained from the connected objected.
\end{abstract}

Index Terms - Internet of things (IoT), higher education, hyper-connectivity, e-learning, physical objects, virtual environment.

\section{INTRODUCTION}

The arrival of Microprocessors in the 1970s created the first mean of PCs (personal computers), followed in the late 1980 s by the network of smart devices concept and enabling the first internet-connected appliance [1]. In 1988, Mark Weiser introduced the ubiquitous computing (many computers for one person) [2], [3]. At the same decade, the United States Defense Advanced Research Projects Agency (DARPA) has been initiated the Distributed Sensor Network (DSN) program in order to survey the experiments in implementing distributed wireless sensor networks [4]. Finally, A decade later, in 1999, Kevin Ashton, a British entrepreneur, invented the term of Internet of Things [IoT] for the first time while was working at Labs Auto-D centers, referring to the RFID) [5].

The basic idea of (IoT) is a new model based on the presence of a variety of objects like Radio Frequency Identification (RFID) tags, sensors and actuators that are able to interact with each other [6].

It is considered as the internetworking of smart physical

Manuscript received October 26, 2016; revised February 20, 2017.

The authors are with National University of Costa Rica, Informatics School, Heredia (e-mail: majid.bayani@ieee.org, enrique.vilchez.quesada@una.cr). objects that are enabled to collect and exchange data through the unique IPv6 addressing schemes. Also, it refers to the use of smartly connected objects, agent and devices to manage data obtained by embedded sensors in machines and other physical-virtual objects. Based on the recommendation of The Global Standards Initiative on Internet of Things (IoT-GSI); IoT has been defined as the global infrastructure for the information society that can facilitate the interconnecting all types of objects such as physical and virtual things based on the presented telecommunication protocols and technologies. IoT-GSI also, emphasized on the establishing a new Study Group on the IoT and its applications, including: smart cities and communities [7].

IoT, based on the Internet society (ISOC), refers to the scenarios where network connectivity and computing capability covers to devices, objects and sensors to generate, send/receive, exchange data without the human intervention [8]. IoT provides the advanced connectivity of objects, devices and systems that goes beyond machine-to-machine (M2M) communications which focuses on the sensor networks - machines communicating. These entire things converse through the cloud technology, make decisions, and share information [9], [10].

By IoT the objects can sense around environment and can be sensed and controlled remotely through existing network infrastructure such as Internet in such a way each object is uniquely detectable through its embedded hardware system and is able to interact within the existing Internetworking architecture [11], [12]. These objects such as the computers, smart-phones, laptops, tablets, phablets, and/or any type of the devices that can receive an IP address comprise the stack of the Internet of Things (IoT). They also, can be joined by other smart devices with/without human intervention which can collect and transfer data, and make a control decision [13].

Predictions for the growth of the IoT are a glimpse into the future: Based on the IDC experts, the worldwide market for IoT solutions grows at a $20 \%$ CAGR from $\$ 1.9$ trillion in 2013 to $\$ 7.1$ trillion in 2020 . More than 20 to 50 billion devices will be connected by 2020 and the worldwide market for IoT solutions will reach to $\$ 7.1$ trillion in four years. It is calculated by 2020 , IoT will impact close to $6 \%$ of the global economy [14].

The 2013 Horizon Report calculates that smart devices will become ubiquitous in higher education by 2017. Also, the Cisco systems forecasts IoT in education has a 10-year net present value of US $\$ 175$ billion, which will be deal out through the personalized instructions, data collection for making efficient decisions and decreasing the overheads on the educational resources [15]. 
IoT is in the early stages and a few applications are currently developed based on it. But it is expected that in future, there will be implemented a large number of the applications for smart systems and ecologies [16].

The scope of IoT application and the technologies that drive it, is extended form the smart connected cities to the healthcare systems. The smart cities, online business, smart homes, smart environment, security \& emergencies, transportation, smart energy consumption, industrial process $\&$ education and monitoring are the most observable examples under the domain of IoT applications. In fact, IoT comprises all macro human/object activities. Education is one of the most visible macro activities in the human life.

Communication Technology has been converted to an essential component in the new education models. It allows passing from a knowledge-transfer model to a collaborative, active, self-directed, and engaging model that helps to increase knowledge and skills of the students (digital students) as well as developing their skills in the "learning digital Society" [15].

As use of IoT implementation in the education area is in the premature steps, there are very dispersed $\&$ limited papers that focused on the usage of IoT on higher education and its measurable impact. This paper presents a descriptive research along with a statistical methodology as a supplementary support. A theoretical analysis on the Internet of education things model and their components will be outlined in the following.

\section{INTERNET OF EDUCATION THINGS MODEL}

The Internet of Things (IoT) has a very relatively new implementation perspective (less than 10 years) in the high education systems [16].

Typically, IoT creates a high capacity ecosystem that provides an open infrastructure for both virtual and physical objects. This potential allows making possible to develop numerous applications based on it [17].

As said, one of the most common applications of IoT is in education, in particular, online education. Online education is, creatively, the most tangible achievement which provides a robust-scalable platform for E-learning that allows to educators and students, as the education objects, work together in the real time. This collaboration can increase, perceptibly, the learning performance, efficiency and the rapid online assessment.

Because of the IoT's nature and the technologies that go along with it such as cloud technology \& virtualization devices, the education agents have access to a big Data-Base of the resources. It means the linking the huge number of institutes around the world which can offer a vast domain of opportunities to the researchers as well as remarkable topics such as accurate predictive and sensibility analysis.

The exclusivity of IoTs' characteristics in the education system applications, especially in higher education allows forming a novel IoT model such as "Internet of Education things (IoET)".

As an assumption, several related features were defined to describe the IoET in order to study the influence of those features in higher education. They are explained in details as follows getting along with a theoretical impact analysis of each pillar that has on the superior education learning process.

\section{A. Engagement in the Learning Process}

If we consider student engagement in education as the degree of attention, interest, inquisitiveness, curiosity, awareness, motivated. optimism, and passion that learners show when they are being taught, which extends to the level of enthusiasm they have to study and improve in their education [16], the two-sided interactive characteristics of the IoT are the effective tools that facilitate more participating of the student in the learning process.

Students by means of the different communication technologies, provided in the IoT learning environment, can answer the questions and/or any type of inquires, questionnaires and giving feedbacks rapidly and frequently. The interactive tools of IoT can contribute the positive youth development. It can make possible forming multi-sized groups of the young students to share their experiences and opinions that ends to the social \& emotional engagement as well as physical and behavioral. Also, the educators can define different educational techniques and strategies in order to capture the learner feedback in real time.

\section{B. Creativity}

In reality, IoT's diversity promotes creativity as a subset of intelligence actions by the capability to observe the world in the new and diverse ways to make connections between physical and virtual objects in such a way it can change the existing domain and transform an existing into a new one [18].

The possibility of interaction between the huge numbers of objects makes it possible to generate the predictable and unpredictable things or ideas.

The Internet of things can encourage creativity in many topics, integrating a wide range of educational technologies which can turn the educators and students into creators.

\section{E-Learning}

Although, the origin of the E-learning phrase that originated during the 1980's is not completely clear but in general, refers to applying electronic tool, soft \& hardware applications and web-based processes to learn [19].

Now days, the prodigious technology evolution and communication tools enable online learning through the huge learning environment names Internet. The IoT can represent an expansion of the learning ecosystem combining the physicality and virtuality, and will come close to the susceptibility of the learning process [20].

IoT can introduce two key factors into the traditional E-learning in a vast domain. They are: intelligence and object interaction (things to everything, machine to machine).

The main function of the Intelligent Agents which offer the automated dynamic operational system is to help a user (an object/smart thing) in order to interact with a computer application [21].

As the E-learning provides a more appropriate virtual access for learners from any geographical position, it also introduces some limitations in the communication, collaboration and "face-to-face" interactions between 
students \& instructors. The solution for these types of issues is using the intelligent objects in the learning environment [21], [22] that IoT is the most limitless provider of interactive smart agents.

In addition, the possibility of cooperation between agents (virtual \& physical objects) in the IoT ecosystem is predicted in a high level of probability.

IoT provides a novel electronic teaching and learning platform with a wide variety of distance learning objects. The virtual object (teacher) interacts with another object (student) as well as interaction between e-classmate objects that generates a different means for collaboration between e-groups. The experiments have shown that using the system based on the intelligent agents can optimize the quality of the system [22].

\section{Self-learning}

Self-learning, auto-didacticism or self-education is the learning act about a subject or subjects in a self-motivated situation without formal education that considered as a complement to education, in order to encourage students to do more independent work [23]. The automation characteristics of the IoT allow to the human objects (students, educators or hardware elements) interacts independently to carry out the educational operational job.

By IoT can integrate the constant self-directed learning into all contexts of human lives because all IoT objects are around of us. They build the whole interconnected world, available to everyone and almost everywhere and every time, interacting with everything.

A student can access to the numerous educational resources any time researching, doing homework, investigating topics of interest, sending and receiving any material or feedback to the educators.

The teachers, by means of IoT, can send and receive any materials from the students as well as the administrative tasks, online student assessment, doing research and connecting to the plentiful research platforms around the world from anywhere connecting to anything. For example, a student can connect by a registered mobile device to the cloud system of institute which is studying form the home or anyplace in the city, checking the possible lab-works (predesigned by teacher), virtually connecting to the lab and experiment the exercises and receive the answer online.

\section{E. Research Opportunity}

The Internet of things can be considered as an interactive methodology in computing which by connecting billions of everyday objects to the Internet; collect huge volumes of information that could reshape the context of the human life.

As it develops, it influences and dominants the content of the social \& professional activities. Working at the same time creates the new opportunities and challenges for industry, education, production and business sections. It enables transforming the means of our life through the unexpected technological changes in the real life efficiency [24].

The rise of ubiquitous object-to-object \& machine-to-machine connectivity is almost everywhere, any time can create many opportunities and challenges for the researchers in different areas of science and technology.
Based on some acknowledged analytical reports [25] the growth of IoT applications and services involve the most desirable topics of the R\&D science groups around the world such as electric vehicles, biology, sporting, healthcare, smart cities \& house, automation, transportation, construction, manufacturing, energy saving, security, telecommunication and more, that are targeted by enormous numbers of the research and development departments related to the institutes and Universities around the world.

It can be also, considered as one of the most revolutionary infrastructure roadmap to support future investment decision in research infrastructure to embrace technological innovation. IoT, as mentioned, is expected to promote significant improvements in the production, education, manufacturing, healthcare, energy, transportation, security, communication, government, and economic growth which means generating innovative modern challenges finding solutions [26].

On the other side, "resources" have a fundamental role in the research process. High grade of real time constant connectivity between different objects (DB, Infrastructures, internetworking) has generated an elevated degree of access to the great volumes of cloud resources that IoT is expected to provide it.

IoT provides connecting the massive number of the institutes, universities and research centers in the real time. This enables the researchers to have access to the big data in order to seek the necessary information for the subjects that are investigating, as well as identifying the future projected topics.

As expected, In IoT all objects and machines around us are connected and lived. Every second they are generating new signals and make connection one-to-many as well as many-to-many type. Also, the local objects can connect to others virtual or physical things through the inter-networking architecture with external things (Internet). In a higher education environment, it means the researchers are living in a $7 / 24 \mathrm{~h}$ of the real-time atmosphere. They can have access to the raining of data they need, or the information related to the original technical facts that, automatically, can generate many challenges for them.

Another motivating side, in this topic, would be: The IoT is projected a growth opportunity for involving the more potential hardware smart devices such as sensors, actuators, networks, servers which can receive an IP address along with the giant cloud infrastructures. It makes possible execution the large volume of analysis in a faster-speed than before.

Intelligent devices with the multiple capacities of observation, monitoring, communication and decision making can transform the research culture to a different era of smart researching in a multiple volume of topics.

In case of M2M, they can observe, monitor, collect and analysis conducted to the novel results and emerging new challenges.

It is predicted in the early future, in an IoT-based environment, the smart-physical-virtual objects can define the future needs of the community based on the input data and past experiences, automatically.

\section{F. Collaboration}


As the recent models of education continues moving towards online or e-learning, a more collaborative ecosystem becomes more and more imperative [27]. IoT provides a big open interactive platform that enhances, effectively collaboration in different layers in the higher education systems. The effective communication is the most fundamental context in the collaboration. IoT can offer the efficient communication between virtual and physical IP-based things with a high degree of interactions. This is because the hyper-connected and interactive nature of IoT.

Technically, it is expected the IoT can create a big and high performance virtual collaboration platform by using the competent tools, sensors, actuators and storage technology. This can be projected as redesigning the traditional collaboration to a new means names the intelligent collaboration.

The intelligent collaboration can be one of the most valuable and novel topics where the multiple users (students or educators in this case) form a team group in order to accomplish predefined tasks of a particular project.

In a typical intelligent collaboration environment, the education objects can schedule their meeting by using the IoT and the peripheral technologies that drive it such as intelligent software, virtual platforms and cloud technology without the location or any physical-place limitation. The functions can be programmed automatically based on the predefined agenda and users can connect, interact and share their knowledge that it means an essential improvement in the collaboration efficiency.

Educators, researchers and students can work together globally, within or out of the education centers or located in different countries without any borders.

\section{G. Hyper-Connectivity}

Based on the Gartner that is the world's leading information technology research and advisory company, the size and scale of the IoT can reach to 26 billion connected devices by 2020. Cisco corporation predicted over 50 billion things will be connected and this number can reach to 75 billion connected objects (physically and/or virtually) as forecasted Morgan Stanley [28].

Hyper connectivity of the IoT in the higher education means connecting numerous academies, institutes and educational centers all over the map. Enormous number of sensors, actuators \& IP-based virtual or physical objects will be connected, generating Big Data. Large amount of information will be generated and available for researchers, instructors as well as the students. The biggest virtual technological platforms will connect all IP-based points over the map, globally. Global video-conference implementation, global institutions and educational centers can be implemented and connect internal education group to the external links.

It is a realistic vision: the worldwide implementation and management of the investigations and projects technically and financially. This global feasible vision is predicted for the future which can transform education style of the human being, all because the hyper connectivity features of IoT.

\section{H. Other factors}

Other influence factors related to this study are considered as indirect indicators; they are: Scalability, Education Object Performance (Student \& Teacher), Cognitive aspects, Learning Efficiency and Big Data (archive).

Scalability as such is one of the intrinsic characteristics concerning by well-designed Internetworking of things.

As the property of IoT, it can be considered a built attribute in the structure and might have the significant influence over the IoT-based education infrastructures. There is no limitation to add or remove any object from the structure and is flexible to the topology changes.

IoT bring with is it Big Data, this is because of the large domain of objects that are enabled to interact and generate large set of Data. It is expected the scalability of IoT in terms of the virtual classrooms size, number of physical and virtual IPv6-based objects, sensors and actuators, and specifically in number of the object Nodes.

Student and teacher performance is a very common indicator that has been discussed by many researchers and there is not any standard parameter for that. But, many researchers tried to study the impact of ICT on the student's achievement and instructor's efficiency [29]-[32].

There is a similarity between ICT and IoT in this theme as well as some essential differences.

The main difference between two concepts is the scope and domain of the IoT, technologically. IoT can cover large parts of the ICT subjects. The use of IoT in higher education might help the students and instructors to share their knowledge and experience in a real time expanded ecosystem.

The speed of sharing and access to the Data generated by other institutes around the world and the volume of the objects involved in the learning process significantly, increases. This characteristic ends to a significant enhancement in the performance of both students and teachers in terms of the learning efficiency.

Some factors such as self-learning, collaboration, learning speed are mainly considered as the essential cognitive learning elements [33].

Using IoT in the education environment has the same effect as ICT-based education systems. It can make the education and learning process more motivating and effective [29].

As discussed, IoT can have direct and indirect influences, in terms of these parameters, in the higher education that are not the focal point in this paper, but they are considered in the statistical questionnaire as a support for this study.

\section{Statistical Methodology}

In order to verify and measure the validity and analysis of the findings in this study, it is used an appropriate statistical methodology as a support to examine the proposed hypothesis in the previous section.

\section{A. Sampling}

A ten item questionnaire is used to collect the related data from participants includes students and instructors. A total of 10 predefined factors using a mixed method approach (verbal and written) were surveyed in this questionnaire. Assuming 
that the goal population is 1000, then the proper sample sizing is determined according to the pilot study by Cochran formula and so, the correct number will be around 257 [22].

Figs. 1 and 2 have presented the graphical illustration of the (teacher \& student)-based questionnaire results. Data obtained in this survey is based on the perception of the University students and instructors both.

\section{B. Results}

Results of the questionnaire revealed that most of teachers believe that IoT is composed of the huge number of hyper-connected objects interacting between themselves.

The results showed a high percentage of instructors (80 to $90 \%$ ) agree with the idea that applying IoT in the higher education ecosystem has a significant influence on the general cognitive aspect of learning such as the learning efficiency and collaboration.

Also, IoT implementation in the higher education institutes, school and universities, effectively, can increase research opportunities for researchers and instructors as well as students.

Fig. 1 predicts statically that IoT might have relatively the weak impact over scalability of Internet of education things. Also, IoT will not help in encouraging the teachers or students to involve in the learning process. Based on the Fig. 1 , the expectancy of the fact that IoT can produce the novel ideas and values in order to change the previous models and replace them by new types is not so high and probably oscillate between 60 and $70 \%$.

Fig. 1 depicts as well, there is a big gap between the (teacher \& student) performance impact and other factors. Almost half percentage of the interviewees thinks IoT doesn't embrace the creativity as part of learning process.

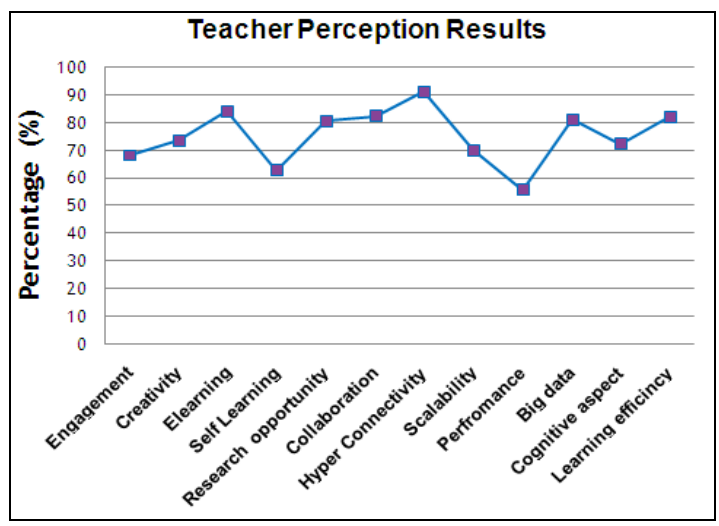

Fig. 1. Graphical representation of the teacher-based questionnaire results.

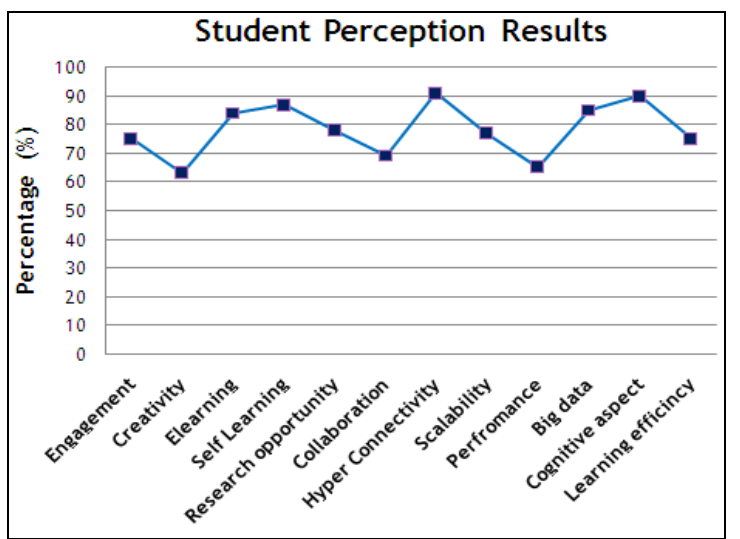

Fig. 2. Graphical representation of the student-based questionnaire results.
The result of student's perception is shown in Fig. 2.

As Fig. 2 demonstrates, in some cases prediction version of the student is different and in other cases has the certain similarities with the teacher's perception. Fig. 3, illustrates a comparison between two prediction versions.

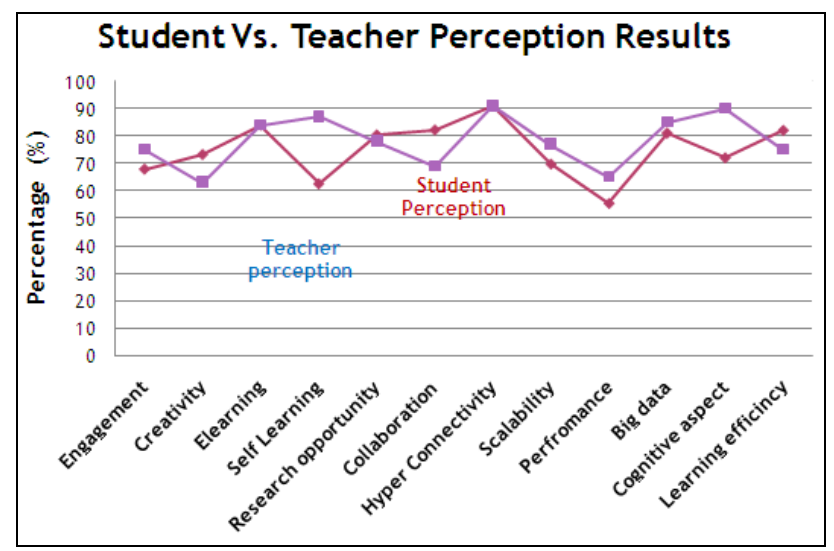

Fig. 3. Comparison between the predictions of teacher-based and student version.

A graphical comparison results is shown in Fig. 3. Based on the Fig. 3, both cases intersect in three factors: E-learning, Research opportunity and Hyper-connectivity. Both groups believe that the IoT has a significant influence on those factors in the higher education IoT ecosystem. The important difference is in case of cognitive learning aspects that the learners consider it, as the main impact factor in the questionnaire. And also, Self-learning factor has an essential place in the opinions of the student that doesn't have the same significance in the teacher view. Influence of the IoT employment in the superior education about the collaboration issue is another difference between two sights. Instructors think that the IoT facilitates significantly effective collaboration and teamwork meanwhile students don't give the same importance as teachers.

Finally, students weakly believe in the fact that the IoT implementation can promote creativity in the higher education and teachers with a little percentage difference don't give a high importance to the same factor as well.

\section{CONCLUSION AND FUtURE WORKS}

This paper explored the possible influence of IoT in the higher education in terms of the various factors. A theoretically analysis was developed in order to study the predicting the possible impact of the IoT on higher education environment and their elements.

Based on the results obtained from the instructor-based questionnaire, it can be concluded that the hyper connectivity is considered as the property of IoT which both interviewee groups believe that the virtually and physically implementation of the IPv6-objects can increase significantly internal interactions between the components of higher education system. As expected, IoT can establish a huge scalable intelligent network digitally interconnecting different institutes, schools and educational centers through the Internet. It means also, IoT can be considered as the biggest flexible virtual education platform that facilitates effective collaboration through increasing more objects in 
terms of the quantity and intelligence, and in a more interactive manner.

IoT technology eliminates the physical presence limitation and expands the access to any education's recourse like teachers, any tools and anywhere facilitating the E-learning efficiently. IoT promises a significant impact on the process of learning in higher education by offering access to the international resources and possibilities for students and teachers. Therefore, one of the major impacts of the IoT-based learning environments is that the conventional student and instructors' tasks can be changed considerably. Students and teachers can retain didactic materials and/or laboratory virtually at any time, from anywhere they can connect. The Internet of things is projected to promote the large number of investigation opportunities for educators, students and researchers around the world. Although it can't contribute the great teacher \& students' performance, but based on the student judge can encourage them to involve in the learning process through the linking the real objects in their tasks, homework, and scientific investigations.

In conclusion, the theoretical and short regional statistical studies show that the effectiveness and influence of the IoT in the higher education and learning process is predictable and shouldn't be ignored.

Flexibility, hyper-connectivity between the real and virtual objects, accessibility, adaptability and scalability are properties of the IoT. They might be considered as the major advantages of the IoT-based learning system which despite of the existing challenges can create new revolution in the higher education ecosystem in the close future. Based on this reality, our future work will be focused on the existing IoT applications in the higher education area.

\section{REFERENCES}

[1] Carnegie Mellon University, "The "only" coke machine on the Internet," Computer Science Department, 2015.

[2] M. Friedemann and C. Floerkemeier, "From the internet of computers to the internet of things," Informatik-Spektrum, vol. 33, issue 2, April 2010 , pp. $107-121$.

[3] M. Weiser, "The computer for the 21st century," Scientific American, vol. 265, issue 3, 1991, pp. 94-104.

[4] Silicon Labs. (2013). The evolution of wireless sensor networks. [Online]. Available: http://www.silabs.com/Support\%20Documents/TechnicalDocs/evoluti on-of-wireless-sensor-networks.pdf

[5] A. Wood, "The internet of things is revolutionizing our lives, but standards are a must," The Guardian, 2015.

[6] R. Parashar, A. Khan, and Neha, "A survey: The internet of things," International Journal of Technical Research and Applications, vol. 4, issue 3, pp. 251-257, May-June 2016.

[7] IoT-GSI. (February 2012). Internet of things global standards initiative. [Online]. Available: http://www.itu.int/en/ITU-T/gsi/iot/Pages/default.aspx

[8] ISOC. (Oct. 2015). The internet of things (IoT): An overview "understanding the issues and challenges of a more connected world. [Online].

Available: https://www.internetsociety.org/sites/default/files/ISOC-IoT-Overvie w-20151014_0.pdf

[9] J. Höller, V. Tsiatsis, C. Mulligan, S. Karnouskos, S. Avesand, and D. Boyle, "From machine-to-machine to the internet of things: Introduction to a new age of intelligence," 2014.

[10] M. Bayani, G. Marin, and G. Barrantes, "Performance e analysis of sensor placement strategies on a wireless sensor network," IEEE Fourth International Conference on Sensor Technologies and Applications, pp. 609-617, 2010.
[11] J. Williams, "Internet of things: Science fiction or business fact?" Harvard Business Review Analytic Services Report, December 2014, pp 2-9.

[12] D. Evans, "The internet of things: How the next evolution of the internet is changing everything," Cisco Corporation, April 2011.

[13] J. O'Brien "Internet of things," EDUCAUSE Review Magazine, July/August 2016, vol. 5, no. 4.

[14] D. Lund, C. MacGillivray, V. Turner, and M. Morales, "Worldwide and regional internet of things (IoT) 2014-2020 forecast: A virtuous circle of proven value and demand," International Data Corporation (IDC), May 2014

[15] M. Selinger, A. Sepulveda, and J. Buchan, "Education and the internet of everything: How ubiquitous connectedness can help transform pedagogy," Cisco Consulting Service and Cisco EMEAR Education Team, October 2013

[16] C. A. V. Rodríguez, M. M. Lavalle, and R. P. Elías, "Modeling student engagement by means of nonverbal behavior and Decision trees," IEEE International Conference on Mechatronics, Electronics and Automotive Engineering (ICMEAE), Nov. 2015, pp. 24-27.

[17] P. Pande and A. R. Padwalkar, "Internet of things - A future of internet: A survey," International Journal of Advance Research in Computer Science and Management Studies, vol. 2, issue 2, February 2014.

[18] M. Csikszentmihalyi, Creativity: Flow and the Psychology of Discovery and Invention Harpercollins, ISBN:9780061844034.

[19] J. L. Moore, C. Dickson-Deane, and K. Galyen, "E-learning, online learning, and distance learning environments: Are they the same?" The Internet and Higher Education, Web Mining and Higher Education: Introduction to the Special Issue, vol. 14, issue 2, March 2011, pp. $129-135$

[20] M. G. Domingo and J. A. M. Forner, "Expanding the learning environment: Combining physicality and virtuality - The internet of things for e-learning," presented at 10th IEEE International Conference on Advanced Learning Technologies, 5-7 July 2010.

[21] A. Jafari, "Conceptualizing intelligent agents for teaching and learning," School of Engineering and Technology Indiana University Purdue University Indianapolis, IUPUI, Educause Quarterly, vol. 25, no. 3, 2002, pp. 28-34.

[22] G. Soava, C. Sitnikova, and D. Danciulescu, "Optimizing quality of a system based on intelligent agents for e-learning," in Proc. 21st International Economic Conference (IECS 2014), May 2014, Sibiu, Romania, pp. 47-55.

[23] J. S. Armstrong, "Natural learning in higher education," Encyclopedia of the Sciences of Learning, 2011.

[24] GSMA Association. (July 2014). Understanding the internet of things (IoT). [Online]. Available: ww.gsma.com

[25] A. O. Vermesan and P. Friess, "Internet of things - From research and innovation to market deployment," River Publishers Series in Communication, 2014.

[26] A. Thierer and A. Castillo, "Projecting the growth and impact of the internet of things," George Mason University, Mercatus Center.

[27] Mercatus. (June 2015). [Online]. Available: https://papers.ssrn.com/sol3/papers.cfm?abstract_id=261879

[28] H. Kratz. (Nov. 9, 2011). The importance of collaboration in higher education. [Online]. Available: https://opensource.com/education

[29] T. Priestley, "Everything is hyper connected in the internet of things," [Online]. Available: https://www.wired.com/insights/2014/08/everything-hyper-connected -internet-things

[30] A. A. Ziden, I. Ismail, R. Spian, and K. Kumutha, "The effects of ICT use in teaching and learning on students' achievement in science subject in a primary school in Malaysia," Malaysia Journal of Distance Education, vol. 13, no. 2, 2011, pp. 19-32.

[31] Olokoba, A. M. Abdullahi, and and S. A. Omosidi, "Impact of information communciation technology (ICT) on the management and performance of secondary school teachers in Kwara State, Nigeria," International Journal of Education Learning and Development, vol. 2, no. 3, August 2014, pp. 60-67.

[32] A. B. Youssef and M. Dahmani, "The impact of ICT on student performance in higher education: Direct effects, indirect effects and organisational Chang," Monograph - The Economics of e-Learning, vol. 5 , no. 1,2008 , pp. $45-56$.

[33] A. Aristovnik, "The impact of ICT on educational performance and its efficiency in selected EU and OECD countries: A non-parametric analysis," Turkish Online Journal of Educational Technology, vol. 11, issue 3, July 2012, pp. 144-152.

[34] M. Bayani, "Influence of simulation and real implementation Skills on the cognitive learning aspects," in Proc. 2012 IEEE 3rd International 
Conference on Cognitive Info-communications, Dec. 2-5, 2012, pp. 719-724.

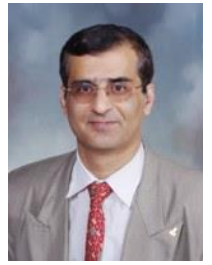

Majid Bayani received his MS degree in computer science from UCR, CR, (Universidad de Costa Rica) and his BS degree in electrical engineering from Sharif University of Technology SUT (IRAN). Since 2009, he has joined the UNA, Heredia, Costa Rica, in 2009 as an instructor and researcher. He has published many papers in the area of computer engineering (among them: IEEE) and participated as a member of technical committee of some international conferences. His main areas of research interest are ICT, information technology and applications, networking, technology management, telecommunication, WSN, modeling internet of things, performance \& simulation, electronic process, digital electronic and virtua world. He is a member of the IEEE (CR section) and currently researching and teaching the computer architecture, networking and communication in the National University of Costa Rica (UNA) as a full time Instructor.

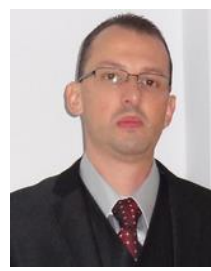

Enrique Vílchez Quesada is a full-time professor and researcher at the National University of Costa Rica (UNA), School of Informatics. He has published more than forty scientific papers in the field of educative computer and mathematics. Also, has participated as a keynote \& invited speaker in more than fifty conferences, at both national and international levels, held in: USA, Brazil, Mexico, Uruguay, Dominican Republic, Cuba, Venezuela, Argentina, Colombia and Costa Rica. His research contributions cover a wide range of topics in mathematics and its applications, information and communication technologies as well as virtual learning. 